\title{
Evaporation of Enriched Uranium Solutions Containing Organophosphates
}

by

\author{
R. A. Pierce
}

Westinghouse Savannah River Company

Savannah River Site

Aiken, South Carolina 29808

M. C. Thompson

This paper was prepared in connection with work done under the above contract number with the U.S. Department of Energy. By acceptance of this paper, the publisher and/or recipient acknowledges the U.S. Government's right to retain a nonexclusive, royalty-free license in and to any copyright covering this paper, along with the right to reproduce and to authorize others to reproduce all or part of the copyrighted paper. 


\section{DISCLAIMER}

This report was prepared as an account of work sponsored by an agency of the United States Government. Neither the United States Government nor any agency thereof, nor any of their employees, makes any warranty, express or implied, or assumes any legal liability or responsibility for the accuracy, completeness, or usefulness of any information, apparatus, product, or process disclosed, or represents that its use would not infringe privately owned rights. Reference herein to any specific commercial product, process, or service by trade name, trademark, manufacturer, or otherwise does not necessarily constitute or imply its endorsement, recommendation, or favoring by the United States Government or any agency thereof. The views and opinions of authors expressed herein do not necessarily state or reflect those of the United States Government or any agency thereof.

This report has been reproduced directly from the best available copy.

Available to DOE and DOE contractors from the Office of Scientific and Technical Information, P.O. Box 62, Oak Ridge, TN 37831; prices available from (615) 576-8401.

Available to the public from the National Technical Information Service, U.S. Department of Commerce, 5285 Port Royal Road, Springfield, VA 22161. 


\section{DISCLAIMER}

Portions of this document may be illegible in electronic image products. Images are produced from the best available original document. 
WESTINGHOUSE SAVANNAH RIVER COMPANY SAVANNAH RIVER TECHNOLOGY CENTER

Evaporation of Enriched Uranium Solutions

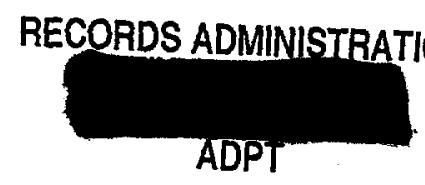

Containing Organophosphates (U)

R. A. Pierce and M. C. Thompson

September 1998 
WESTINGHOUSE SAVANNAH RIVER COMPANY

SAVANNAH RIVER TECHNOLOGY CENTER

\title{
Evaporation of Enriched Uranium Solutions \\ Containing Organophosphates (U)
}

\author{
R. A. Pierce and M. C. Thompson
}

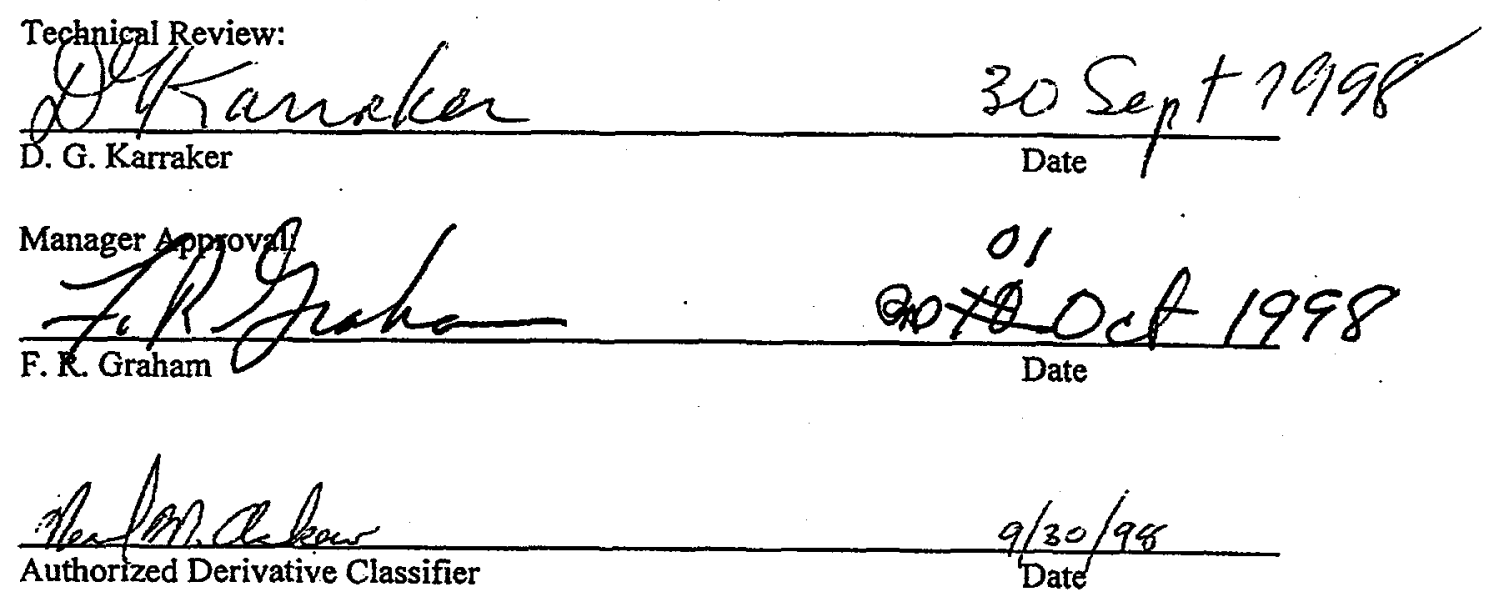




\section{ABSTRACT}

The Savannah River Site has enriched uranium (EU) solution which has been stored for almost 10 years since being purified in the second uranium cycle of the $\mathrm{H}$ area solvent extraction process. The concentrations in solution are $\sim 6 \mathrm{~g} / \mathrm{L} \mathrm{U}$ and about $0.5 \mathrm{M}$ nitric acid. Following processing, the solutions are allowed to contain as much as $0.5 \%$ by volume of organic before going to the evaporator. Residual tributylphosphate in the solutions has slowly hydrolyzed to form dibutyl phosphoric acid at concentrations averaging $50 \mathrm{mg} / \mathrm{L}$. Uranium is known to form compounds with the dibutylphosphate ion (DBP) which have limited solubility. The potential to form uranium-DBP solids raises a nuclear criticality safety issue. The results of this study, in conjunction with earlier data, suggest that if EUS solutions are acidified and evaporated, the margin of safety for their storage will increase. The level of increase in the safety margin is a function of the time the EUS solution is maintained at boiling during evaporation (due to DBP losses) and the final acid concentration (due to DBP solubility changes as a function acid concentration).

Prior SRTC tests discussed the solubility of U-DBP at various conditions and showed that solids can precipitate at concentrations potentially attainable during the storage of enriched uranium solutions. The same potential exists for the evaporation of unwashed ICU solutions. Data in the literature proposes that in heated nitric acid solutions, TBP can be slowly degraded to DBP and DBP can be slowly converted to monobutylphosphate. As a follow-up to the earlier studies, SRTC studied the possibility of using acidification followed by evaporation as a way to reduce the probability of precipitating U-DBP solids by raising the EUS acid concentration to levels where DBP solubility increases. It was demonstrated that there is an upward shift in DBP solubility between $0.5 \mathrm{M}$ and $1.0 \mathrm{M}$ acid for $12 \mathrm{~g} / \mathrm{L} \mathrm{U}$ samples and between $1.0 \mathrm{M}$ and $2.0 \mathrm{M}$ for $6 \mathrm{~g} / \mathrm{L} \mathrm{U}$ samples

The preliminary data obtained in this set of tests reveals that DBP is gradually eliminated from solution during evaporation at rates consistent with those reported in the literature. It is not clear whether the losses are due to degradation or evaporation. The data also shows that TBP readily strips from solution in the absence of uranium, and that TBP is partially retained in the presence of uranium. The effect of uranium on DBP losses appears to be small. This is very important in considering the handling and storage of future 1CU solutions. The limited scope of the experiments did not make it possible to determine the rates of TBP conversion to DBP. Additional work will be needed to better understand and quantify the effects of evaporation on solutions containing TBP, DBP, uranium, and nitric acid.

The preliminary SRTC data, in conjunction with information in the literature, is promising. However, very few experiments have been run, and none of the results have been confirmed with repeat tests. As a result, it is believed that insufficient data exists at this time to support Separations making any process or program changes based on the information contained in this report. 


\section{INTRODUCTION}

The Savannah River Site has enriched uranium (EU) solution which has been stored for almost 10 years since being purified in the second uranium cycle of the $\mathrm{H}$ area solvent extraction process. The concentrations in solution are $\sim 6 \mathrm{~g} / \mathrm{L} \mathrm{U}$ and about $0.5 \mathrm{M}$ nitric acid; the solution was recently acidified from $0.1 \mathrm{M}$ using $64 \%$ nitric acid. Following Canyon processing, the solutions can contain as much as $0.5 \%$ by volume of organic before going to the evaporator. Residual TBP in the solutions has slowly hydrolyzed to form dibutyl phosphoric acid at concentrations averaging $50 \mathrm{mg} / \mathrm{L}$. Uranium is known to form compounds with the dibutylphosphate ion (DBP) which have limited solubility. ${ }^{1,2}$ The potential to form uranium-DBP solids raises a nuclear criticality safety issue.

Because of the nuclear criticality issue, process approaches are being reviewed that can increase the inherent margin of safety for the storage of the EUS solution. Earlier studies evaluated the solubility limits for a wide range of possible storage conditions. ${ }^{3.4}$ These studies show the benefits of evaporation to higher acid concentrations because there is a clear upward shift in DBP solubility between $0.5 \mathrm{M}$ and $1.0 \mathrm{M}$ acid for $12 \mathrm{~g} / \mathrm{L}$ $\mathrm{U}$ samples and between $1.0 \mathrm{M}$ and $2.0 \mathrm{M}$ for $6 \mathrm{~g} / \mathrm{L} \mathrm{U}$ samples. ${ }^{4}$ A recommendation based on that data involves acidification of the uranium solution followed by evaporation to raise the acid concentration to the regime where higher'DBP solubility occurs.

Data in the literature also indicates that hydrolysis reactions slowly convert TBP to DBP and also DBP to monobutylphosphate (MBP) in acidic solutions. ${ }^{12,5}$ The same reports show how the rates of hydrolysis vary as a function of acid concentration, temperature, and time. Other literature sources also discuss the effects of elevated temperature operations on TBP concentrations. ${ }^{6.7}$

This report discusses experiments aimed at determining the effects of evaporation on solutions containing TBP and/or DBP. Tests will measure TBP, DBP, and acid concentrations during evaporation as a function of time. Based on the test results and the findings of earlier studies, it will be possible to conclude whether or not evaporation of the EUS solutions will produce a more favorable storage condition.

\section{EXPERIMENTAL}

\section{Sample Preparation}

Solutions were prepared with various mixtures of reagent grade $\mathrm{HNO}_{3}$, uranyl nitrate hexahydrate (UNH), $98 \%$ pure DBP solution obtained from Aldrich, and TBP and n-paraffin. The TBP and n-paraffin are the same as used in the SRS Separations facilities. A stock solution of UNH was prepared in glass volumetric flasks with $0.5 \mathrm{M} \mathrm{HNO}_{3}$ prepared from $15.7 \mathrm{M}$ acid and $\mathrm{UNH}$. The $\mathrm{UNH}$ solution containing $150 \mathrm{~g} / \mathrm{L} \mathrm{U}$ was prepared by dissolving $79.20 \mathrm{~g}$ of $\mathrm{UNH}$ solids in a $250 \mathrm{~mL}$ volumetric flask using $0.5 \mathrm{M} \mathrm{HNO}_{3}$ and diluting to the mark.

The DBP solutions was made by dissolving $0.1138 \mathrm{~g}$ of DBP in a $100 \mathrm{~mL}$ volumetric flask using $0.5 \mathrm{M} \mathrm{HNO}$ and diluting to the mark. The nominal DBP concentration based on $98 \%$ purity is $1115 \mathrm{mg} / \mathrm{L}$. A $30 \% \mathrm{TBP}$ in $\mathrm{n}$-paraffin solution was taken from previous experiments in which $2400 \mathrm{~mL}$ of TBP was combined with 5600 $\mathrm{mL}$ of $\mathrm{n}$-paraffin (n-P). The stock solutions were then used to prepare test solutions.

\section{Experimental Procedures}

Five experiments were conducted to simulate operation of the evaporator. The first two tests operated with TBP in different concentrations of nitric acid. The third experiment studied the impact of evaporation on DBP in the presence of nitric acid. Test 4 used a mixture of nitric acid, TBP and DBP, and Test 5 combined nitric acid, TBP, DBP, and depleted uranium to evaluate process behavior. 
The first four experiments were conducted in the H-Canyon evaporator model that is made completely from glass (Attachment 1). The evaporator contains a bottom pot with 1.5 liters of capacity. Above the pot is a section with three trays of bubble caps to provide distillation stages and de-entrainment; the section of bubble caps mimics the three trays of bubble caps in H-Canyon. Above the bubble caps is an overheads condenser which can reflux condensate back to the section of bubble caps or discharge it from the system. The system is heated using a standard heating mantle without stirring. Solution is fed to the evaporator using a variable-speed Cole-Parmer peristaltic pump.

In the first test, $1340 \mathrm{~mL}$ of solution was prepared containing $0.35 \mathrm{M}$ nitric acid and $6.2 \mathrm{~mL}(0.46 \mathrm{vol} . \%)$ of $30 \% \mathrm{TBP} / \mathrm{n}$-P. Samples for TBP $(97 \mathrm{~mL})$ and DBP $(3 \mathrm{~mL})$ were removed. The evaporator was charged with $400 \mathrm{~mL}$ of solution and the heat was turned on. When the solution began boiling, the feed pump was turned on at a feed rate of $3.5 \mathrm{~mL} / \mathrm{min}$; heating is manually regulated to control the evaporation rate at $3.5 \mathrm{~mL} / \mathrm{min}$. The feed pump was left running until the remaining $840 \mathrm{~mL}$ of feed solution was added. Samples were withdrawn every 30 minutes to analyze the acid concentration of the evaporator pot and the condensate. Samples were withdrawn each hour for DBP analysis. Samples of the final evaporator pot and condensate were submitted to analyze for TBP. Samples were not withdrawn from the bubble cap trays. The second test was conducted similar to the first experiment except that the starting nitric acid concentration was prepared at a concentration of $1.0 \mathrm{M}$.

For the third experiment, $915 \mathrm{~mL}$ of $0.6 \mathrm{M}$ nitric acid was prepared containing $60-70 \mathrm{mg} / \mathrm{L}$ of DBP. A sample for DBP ( $3 \mathrm{~mL}$ ) was removed. The evaporator was charged with $400 \mathrm{~mL}$ of solution and the heat was turned on. When the solution began boiling, the feed pump was turned on at a feed rate of $3.5 \mathrm{~mL} / \mathrm{min}$; heating is manually regulated to control the evaporation rate at $3.5 \mathrm{~mL} / \mathrm{min}$. The feed pump was left running until the remaining $512 \mathrm{~mL}$ of feed solution was added. When feeding was complete, the system was set up-for complete reflux of condensate and the system was heated for an additional six hours. Samples were withdrawn every 30 minutes during feeding and every hour after feeding to analyze the acid concentration of the evaporator pot. Samples were withdrawn throughout the test for DBP analysis; final condensate and bubble cap tray samples were also submitted for DBP analysis.

In the fourth test, $965 \mathrm{~mL}$ of $0.6 \mathrm{M}$ nitric acid was prepared containing $60-70 \mathrm{mg} / \mathrm{L}$ of $\mathrm{DBP}$ and approximately $150 \mathrm{mg} / \mathrm{L}$ of TBP. Samples for TBP $(47 \mathrm{~mL})$ and DBP $(3 \mathrm{~mL})$ were removed, leaving $915 \mathrm{~mL}$ for the evaporation test. The evaporator was charged with $400 \mathrm{~mL}$ of solution and the heat was turned on. When the solution began boiling, the feed pump was turned on at a feed rate of $3.5 \mathrm{~mL} / \mathrm{min}$; heating is manually regulated to control the evaporation rate at $3.5 \mathrm{~mL} / \mathrm{min}$. The feed pump was left running until the remaining $515 \mathrm{~mL}$ of feed solution was added. When feeding was complete, the pump and the heating were turned off. Samples were withdrawn only at the end of the run for TBP, DBP, and acid concentration analysis; samples were pulled from the evaporator pot, condensate, top bubble cap tray, and $1^{\text {st }} / 2^{\text {nd }}$ bubble cap trays.

The SRTC Glass Shop fabricated a separate unit for tests with uranium to avoid contaminating the H-Canyon evaporator model (Attachment 2). This unit contains an evaporator pot with approximately $600 \mathrm{~mL}$ of capacity. Attached to the evaporator pot is a condenser packed with beads; the condenser is fabricated with a reflux collection section positioned between the evaporator pot and the beads. In this test, $510 \mathrm{~mL}$ of $0.6 \mathrm{M}$ nitric acid was prepared containing $60-70 \mathrm{mg} / \mathrm{L}$ of $\mathrm{DBP}, 160-170 \mathrm{mg} / \mathrm{L}$ of TBP, and $6 \mathrm{~g} / \mathrm{L}$ depleted uranium. Samples for TBP $(47 \mathrm{~mL})$ and DBP $(3 \mathrm{~mL})$ were removed. The evaporator was charged with $230 \mathrm{~mL}$ of solution and the heat was turned on. When the solution began boiling, $18 \mathrm{~mL}$ of feed solution was added every 10 minutes; heating is manually regulated to control the evaporation pot volume at $200 \mathrm{~mL}$. When feeding was complete and the evaporator volume was near $200 \mathrm{~mL}$, the heating was turned off. Samples were withdrawn only at the end of the run for TBP, DBP, and acid concentration analysis; samples were pulled from the evaporator pot, condensate, and condenser reflux collection. 


\section{Analyses}

DBP analyses were done by ion chromatographic analysis (IC). Considerable effort has been made to improve the DBP analysis method to obtain reproducible results with the lowest uncertainty; ${ }^{1}$ DBP uncertainty is on the order of $+1-10 \%$. Analysis of TBP was conducted using gas chromatography with an uncertainty of $+1-20 \%$. Nitric acid concentrations were determined using acid-base titration with phenolphthalein indicator.

\section{RESULTS AND DISCUSSION}

Previous testing showed that higher acid concentrations offer potentially higher levels of U-DBP solubility due to an upward solubility shift between $0.5 \mathrm{M}$ and $2.0 \mathrm{M}$ nitric acid (Figure 1 ). ${ }^{4}$ In practice, a higher acid concentration would involve two process steps, acidification followed by evaporation. This is because normal evaporation is limited by the uranium concentration, thereby limiting the level to which the nitric acid can be concentrated through evaporation only. The tests discussed in this report address whether or not the evaporation of solutions containing both TBP and DBP in the presence of uranium increases DBP levels due to TBP degradation, or decreases DBP levels due to DBP degradation and/or evaporation.

The initial experiments evaluated the behavior of TBP in nitric acid during

\section{Figure 1. High Acid Solubility of U-DBP}

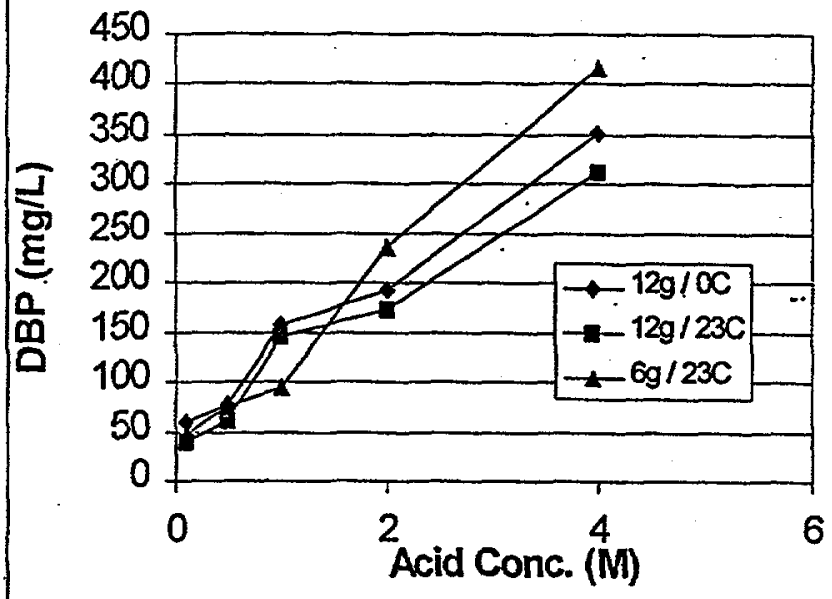
evaporation. In the initial two runs, testing with TBP in the absence of both DBP and uranium was performed to measure the combined effect of TBP evaporation from and hydrolysis in the evaporator. The only difference between the two experiments is that Test \#1 started with $0.36 \mathrm{M} \mathrm{HNO}_{3}$ and Test \#2 began with $1.05 \mathrm{M} \mathrm{HNO}$. The data is listed in Table 1.

Table 1. TBP Evaporation Data in the Absence of HDBP and Uranium

$\begin{array}{cc}\text { TBP } & (\mathrm{mg} / \mathrm{l}) \\ \text { TEST \#1 } & \text { TEST \#2 } \\ & \\ 1300 & 1600 \\ 91 & 28 \\ 78 & 44 \\ 71 & \text { nd } \\ \text { nd }=\text { not detectable }\end{array}$

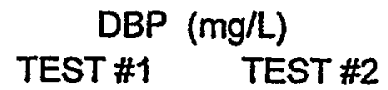

Start Solution

Final Solution

Condensate $-2 \mathrm{Hr}$.

Condensate $-4.5 \mathrm{Hr}$

\section{TEST \#1 TEST \#2}

$\begin{array}{ll}b q & b q \\ b q & b q \\ b q & b q \\ b q & b q\end{array}$

$b q=$ below quantitation limit

As seen from the data, TBP is readily steam-stripped from the evaporator into the overheads. Also, the stripping of TBP from the system is rapid enough that little potential exists for developing a measurable level of DBP in the evaporator. The results for both are consistent with what has been reported earlier ${ }^{6-3}$. However, a material balance cannot be performed because the liquid from the evaporator trays was not collected for analysis. Furthermore, it is also believed that a high potential exists for an organic film to build up on one of 
the many surfaces of the evaporator such that it would not show up in the analysis for a single experiment. The high value for the starting solution is probably skewed high. The reported solubility for $30 \%$ TBP in these types of solutions is on the order of $380-420 \mathrm{mg} / \mathrm{L}$.? It is expected that the high value is the result of erroneously sampling the starting liquid from the top of the solution where a less-dense TBP film would reside.

The third experiment studied the impact of evaporation on DBP in the presence of nitric acid. The experiment was run similar to the first two. In addition, when feeding of the evaporator was complete after 2.5 hours, the evaporator was run under total reflux conditions for 6 hours to determine if measurable DBP degradation occurs. The final volumes measured for the evaporator pot, trays, and condensate were $370 \mathrm{~mL}, 155 \mathrm{~mL}$, and $340 \mathrm{~mL}$, respectively (unaccounted $=35 \mathrm{~mL}$ ). A total of $15 \mathrm{~mL}$ was also removed through sampling. The DBP data for all samples is shown in Table 2.

Table 2. DBP Evaporation Data in the Absence of TBP and Uranium (TEST 3)

\begin{tabular}{|c|c|c|c|c|c|c|c|}
\hline $\begin{array}{c}\text { Time } \\
\text { (hours) }\end{array}$ & $\begin{array}{l}\text { Measured } \\
\text { DBP (ppm) }\end{array}$ & $\begin{array}{c}\text { Measured } \\
\mathrm{H}+(\mathrm{M})\end{array}$ & $\begin{array}{l}\text { Calculated } \\
\text { DBP (ppm) }\end{array}$ & $\begin{array}{c}\text { Calculated } \\
\text { DBP after } \\
\text { Degradation }\end{array}$ & $\begin{array}{c}\text { Percent } \\
\text { Difference }\end{array}$ & & \\
\hline 0 & 59 & 0.62 & 59 & 59 & - & & \\
\hline 1 & 106 & 1.28 & 122 & 119 & 10.74 & & \\
\hline 2 & 101 & 1.18 & 112 & 107 & $5.32 \ldots$ & & \\
\hline 2.5 & 96 & 1.07 & 102 & 96 & 0.52 & & \\
\hline 3.5 & 95 & 1.13 & 108 & 99 & 4.39 & & $\ldots$ \\
\hline 5.5 & 114 & 1.39 & 132 & 116 & 1.88 & 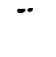 & \\
\hline 8.5 & 118 & 1.51 & 144 & 117 & 0.86 & & \\
\hline Condensate & 34 & & & & & & \\
\hline Trays & nd & & & & & & \\
\hline
\end{tabular}

The "Calculated DBP" column of Table 2 is a function of the acid concentration increase and the total DBP added to the system. The "Calculated DBP After Degradation" column takes into account the acid concentration increase, the total DBP added, and a reported DBP degradation rate of $2.5 \%$ per hour for DBP in 1.0M HNO ${ }_{3}$ at boiling. ${ }^{3}$ The "Percent Difference" column is a comparison between the measured DBP and the degradation-adjusted DBP values. As can be seen from Table 2, there is a strong correlation between the data of Test \#3 and that reported in the literature.

A question does develop regarding the material balance and whether the DBP degrades or steam strips. The total DBP added to the system $54.0 \mathrm{mg}(915 \mathrm{~mL}$ start solution @ $59 \mathrm{mg} / \mathrm{L})$. The DBP accounted for in the data is $56.8 \mathrm{mg}$-this includes DBP in the withdrawn samples (assumed to be $100 \mathrm{mg} / \mathrm{L} \mathrm{DBP}$ ) plus the DBP in the condensate plus the DBP in the final evaporator solution). This gives a material balance of $105 \%$ that is well within the $10 \%$ uncertainty in the DBP analysis. The data suggests that the primary method of DBP loss during evaporation is through evaporation rather than degradation. However, within the error of the analyses, it is possible that an equivalent amount of DBP degradation is also occurring. The available data in the literature and previously measured at SRS is not conclusive, ${ }^{1,7.8}$

The fourth experiment was run in a manner similar to the first and second test with the exception that both TBP and DBP were included in the feed stream. The test intends to show any interaction between the TBP and DBP that either increases or decreases TBP/DBP losses. After the evaporator run, the system volumes were recorded (unaccounted volume $=31 \mathrm{~mL}$ ). The data listed in Table 3 is somewhat consistent with the observations for the previous tests.

Two data points for the TBP are significantly different than what was observed earlier. The final pot TBP value is much lower. Even so, this is consistent with the literature. Furthermore, a second analysis of the sample 
confirmed that the value is of the proper order of magnitude. The condensate value is unexpectedly high and above the reported solubility levels for TBP in water. Similar to the TBP concentrations observed for the starting solutions of Tests 1 and 2 , it is proposed that there may have been an organic film on the surface of the sample that skews the measured value. The high value for TBP in the condensate makes it impossible to perform a mass balance. The high value for TBP could be the result of poor sampling in which an organic film is present on top of the solution and skews the data high. However, if a solubility value consistent with the literature value is used $(400 \mathrm{mg} / \mathrm{L})$, the TBP mass balance for the system is $93.0 \%$, and is well within the accuracy of the measurements.

Table 3. TBP/DBP Evaporation Data in the Absence of Uranium (TEST 4)

\begin{tabular}{|c|c|c|c|c|c|c|}
\hline Sample & $\begin{array}{c}\text { Volume } \\
(\mathrm{mL})\end{array}$ & $\begin{array}{c}\text { Measured H+ } \\
\text { (M) }\end{array}$ & $\begin{array}{l}\text { Measured TBP } \\
\text { (ppm) }\end{array}$ & $\begin{array}{c}\text { Total TBP } \\
\text { (mg) }\end{array}$ & $\begin{array}{l}\text { Measured DBP } \\
\text { (ppm) }\end{array}$ & $\begin{array}{c}\text { Total DBP } \\
\text { (mg) }\end{array}$ \\
\hline Feed Liquid & 915 & 0.59 & 168 & 153.7 & 68 & 62.2 \\
\hline Final Pot & 480 & 1.13 & 1.0 & 0.5 & 93 & 44.6 \\
\hline Condensate $^{*}$ & 345 & $<0.002$ & $1263 / 400^{*}$ & 138.0 & 29 & 10.0 \\
\hline 1st/2nd Trays & 30 & 0.024 & 130 & 3.9 & 35 & 1.1 \\
\hline Top Tray & 29 & $<0.004$ & 1.5 & 0.0 & 34 & 1.0 \\
\hline
\end{tabular}

The DBP data is also consistent with the results from Test \#3. One significant difference between the two data sets is the presence of DBP in the evaporator trays. It is proposed that Test \#3 showed no DBP in the trays because the system had been subjected to six hours of reflux conditions; during refluxing, all DB̈P became caught up in the top section of the condenser. Test \#4 does not reflux the DBP. Rather, heating is discontinued shortly after feeding is stopped. As a result, the DBP has not been stripped from the trays into the condensate. The DBP data for Test \#4 exhibits a mass balance of $91.3 \%$. This is also within the accuracy of the analyses.

The final experiment was run in a similar fashion, but on an evaporator system with smaller volumes and ceramic saddles for packing instead of bubble cap trays (Attachment 2). The last test also included approximately $6 \mathrm{~g} / \mathrm{L}$ of depleted uranium in the feed stream. Upon completion of the evaporation run, the system volumes were measured (unaccounted volume $=34 \mathrm{~mL}$ ). The data for this test is included in Table 4 .

Table 4. U/TBP/DBP Evaporation (TEST 5)

$\begin{array}{ccccccc}\text { Sample } & \begin{array}{c}\text { Volume } \\ (\mathrm{mL})\end{array} & \begin{array}{c}\text { Measured H+ } \\ (\mathrm{M})\end{array} & \begin{array}{c}\text { Measured TBP } \\ (\mathrm{ppm})\end{array} & \begin{array}{c}\text { Total TBP } \\ (\mathrm{mg})\end{array} & \begin{array}{c}\text { Measured DBP } \\ (\mathrm{ppm})\end{array} & \begin{array}{c}\text { Total DBP } \\ (\mathrm{mg})\end{array} \\ \text { Feed Liquid } & 460 & 0.6 & 150 & 69.0 & 56 & 25.8 \\ \text { Final Pot } & 171 & 1.4 & 75 & 12.8 & 86 & 14.7 \\ \text { Condensate } & 22 & <0.1 & 35 & 0.8 & 7 & 0.2 \\ \text { Condenser } & 233 & <0.1 & 98 & 22.8 & 8 & 1.9\end{array}$

The data from Test \#5 is similar to the data collected from the earlier experiments. It must be noted that the TBP mass balance for this test is a mere $49.4 \%$. It is unclear whether the poor mass balance is caused either by sampling and analytical errors or by hold-up and absorption onto the ceramic saddles used as packing for the condenser. An argument for the absorption onto the ceramic saddles is very credible. Additional work will be required to resolve this issue.

Another significant difference between Test \#5 and the other tests is the lack of DBP appearing in the condenser and condensate. One potential cause is the presence of complexes of uranium and DBP that limit DBP volatility. However, the material balance for the DBP is also very low at $64.7 \%$. It is possible that this is 
caused by accelerated degradation of DBP by uranium (a phenomenon reported to occur with TBP). However, it is unlikely that this accounts for the large discrepancy - if it did, the DBP levels in the EUS tanks would be much lower. The poor material balance may be attributed to either experimental or analytical error. A third explanation, similar to TBP, is that DBP is being held up or absorbed by the condenser packing. Once again, additional studies are needed.

\section{CONCLUSIONS}

A combination of acidification with evaporation offers a potential method for increasing the safety margins for the storage of EUS solutions. The benefit of this approach comes from the gradual loss of DBP during heating and the ability to concentrate the acid so that the solution enters a higher solubility regime. The use of evaporation appears to either gradually degrade or evaporate DBP at approximately $2.5 \%$ per hour. Also, previous studies suggest that those solutions with acid concentrations above 1.0-2.0M exhibit higher degrees of DBP solubility than would be predicted from calculations that assume no changes in U-DBP chemistry. At this time, it is questionable whether or not the benefit gained from evaporation will be worth the effort required to evaporate the solutions. Additional work is still needed to verify and better quantify the effects observed during these experiments.

The data also shows a clear benefit for processing future 1 CU solutions. Test results indicate that steam stripping of TBP from nitric acid during evaporation is significant regardless of whether uranium is present or not. In all relevant tests, the final TBP concentration in the evaporator bottoms was below the-DBP solubility limit. This means that even if all TBP was converted to DBP, the solutions could still be stored safely. As a result, evaporation can be used to steam strip residual TBP from ICU solutions, thereby eliminating the source of the DBP that is formed during storage.

The preliminary SRTC data, in conjunction with information in the literature, looks promising. However, very few experiments have been run, and none of the data points have been confirmed with duplicate tests. As a result, it is believed that insufficient data exists at this time to warrant Separations making any process or program changes based on the information contained in this report. When this data is confirmed in future testing, recommendations will be presented.

\section{REFERENCES}

1. E. K. Dukes. The Formation and Effects of Dibutyl Phosphate in Solvent Extraction, DP-250, E.I. du Pont de Nemours \& Co., November 1957.

2. V. J. Reilly. The Hydrolysis of Tributyl Phosphate and Its Effect on the Purex Process, ORNL-I138, Oak Ridge National Laboratory, December 1951.

3. R. A. Pierce, M. C. Thompson, and R. J. Ray. Solubility Limits of Dibutyl Phosphoric Acid in Uranium Solutions at SRS, WSRC-TR-98-00188, Westinghouse Savannah River Co., August 1998.

4. R. A. Pierce and M. C. Thompson. Dibutyl Phosphoric Acid Solubility in High-Acid, Uranium-Bearing Solutions at SRS, WSRC-TR-98-00281, Westinghouse Savannah River Co., September 1998.

5. R. Becker, L. Stieglitz, and H. Bautz. Determination of the Hydrolysis Constants of TBP, HDBP, and $\mathrm{H}_{2} \mathrm{MBP}$ in 3M Nitric Acid, Report No. 96/81, Karlsruhe Nuclear Research Center Ltd., November 1981.

6. G. S. Barney and T. D. Cooper. The Chemistry of Tributyl Phosphate at Elevated Temperatures in the Plutonium Finishing Plant Process Vessels, WHC-EP-0737, Westinghouse Hanford Co., 1994.

7. L. Stieglitz, R. Becker, H. Bautz, and R. Will. Properties of Heavy Organic Phases and their Formation in the Purex Process, ISEC 86, pp. I-239, 1986.

8. J. H. Gray. Evaporator Test Result Summary. WSRC Internal Memorandum, Westinghouse Savannah River Company, January 1996.

9. W. W. Schulz and J. D. Navratil. Science and Technology of Tributyl Phosphate, Vol. 1, CRC Press Inc., Boca Raton, FL (1984). 


\section{ATTACHMENTS}

Attachment 1 - H-Canyon Decanter Model

Attachment 2 - Radioactive Demonstration Unit 


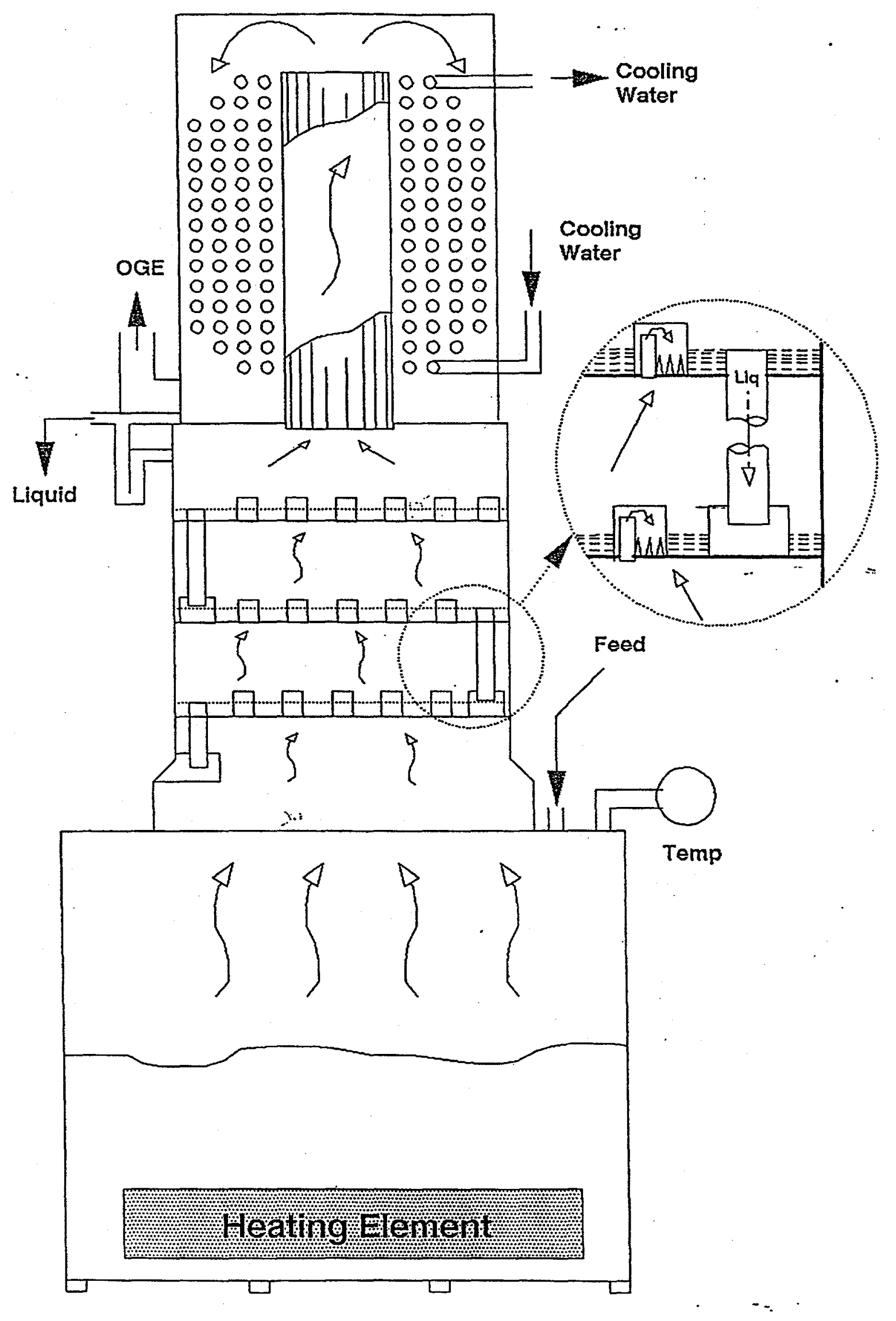




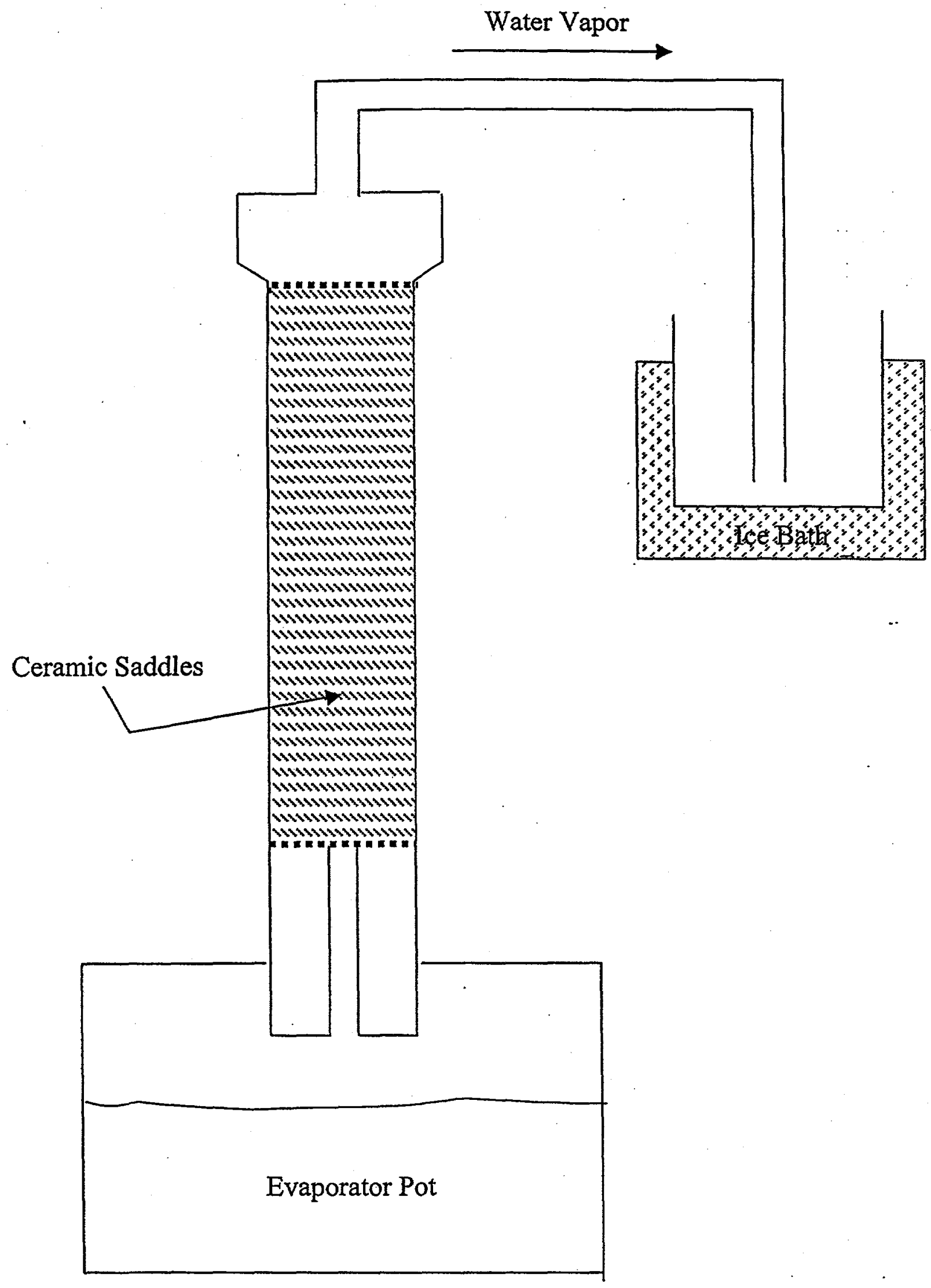

